\title{
Guide to GIVD's Fact Sheets
}

\author{
Falko Glöckler, Jürgen Dengler, Florian Jansen, Jens Oldeland \& Robert K. Peet
}

\begin{abstract}
This article explains the fields that are used to provide an overview of the metadata for each database in the Global Index of Vegetation-Plot Databases (GIVD). The Fact Sheets published in the Long and Short Database Reports of this volume try to answer the readers' questions on availability, scope, format, status, completeness, amount of data, applied methods, and several more in a condensed compilation.
\end{abstract}

Keywords: ecoinformatics; Global Index of Vegetation-Plot Databases; metadata; phytosociology; relevé; overview; template.

Abbreviations: GIVD = Global Index of Vegetation-Plot Databases; ISO = International Organization for Standardization; URI = Uniform Resource Identifier.

\section{Background}

Within the Global Index of VegetationPlot Databases (GIVD; see Dengler et al. 2011), the curators of vegetation-plot databases upload relevant metadata on their databases and the data they contain. The complete and continuously updated metadata are available from the Internet platform http://www.givd.info. This volume on Vegetation databases for the 21st century presents the most important facts of the GIVD-registered databases as of 12 June 2012. This overview is slightly more recent than the data underlying the analyses of Jansen et al. (2012), causing some minor deviations.

To summarise the key information in a standardised and informative manner, we developed the half-page GIVD Fact Sheets (Fig. 1). These Fact Sheets are part of the 21 Long Database Reports (pp. 91286) and the 149 Short Database Reports (pp. 247-447). Only 33 of the 182 registered GIVD databases to date are not presented by a Database Report here (see Glöckler 2012), either because they are only planned and thus do not contain any plot yet or because their curators chose not to include them in this publication. The Fact Sheets have been generated automatically from the information contained in GIVD, but checked for consistency and formatting issues prior to publication. In case of Short Database Reports, the Fact Sheets are complemented by an abstract supplied by the curator(s), while the Long Database Reports (where the Fact Sheets appear always on the second page) are full scientific articles with much more detailed background information on the respective databases.

The intent of this guide is to assist readers in understanding and extracting the condensed information contained in the Fact Sheets. To this end, we give definitions of those GIVD metadata fields selected for Fact Sheets. Referring to the field numbers given in Figure 1, we explain the meaning briefly in Table 1 and in more detail in the text. Further information on all GIVD metadata fields is available from http://www.givd.info/fileadmin/ GIVD/downloads/Dengler_et_al_GIVD_

AVS_Appendix_S1_v04.pdf, including those metadata fields not included in the Fact Sheets or only in an abbreviated manner.

\section{Definitions of the fields in the Fact Sheets}

The Fact Sheets start with very basic information including the GIVD database ID (1), the date of last update (2) of the metadata, and the database name (3). The database name is a proper name (thus capitalised), an acronym, or a full name with acronym in brackets. In the GIVD online version, the users can additionally upload an explanatory subtitle (which is considered not part of the proper name); this subtitle appears in the title of the
Short Database Reports in the overview of Glöckler (2012), separated by an en-dash. The database ID is tripartite and provided by the GIVD Steering Committee according to the geographic origin of the contained vegetation plots and the sequence of registration to guarantee uniqueness and persistence. The first part indicates the continent (see Table 2), the second the country according to its alpha-2 ISO code (http://www.iso.org/iso/country_codes. htm; see Table 3). For example, does the GIVD ID $A F-Z A-001$ indicate that this is the first-registered database from South Africa (ZA) in Africa (AF). If a database contains a significant amount of vegetation plots from more than one country or continent, the respective part of the GIVD ID is replaced by "00" (e.g. EU-00-001, 00-RU-001). In the case of Russia, databases are called multicontinental, if they contain data from both west and east of the Ural Mountains. The terminal threedigit number is a simple counter according to the sequence of registration to differentiate databases from the same country. The Fact Sheets are colour-coded according to the continents (Table 2). Both the Long and the Short Database Reports are sorted according to the GIVD ID, starting with the multicontinental databases, and followed by the continents in alphabetical order of their two-letter abbreviation (Table 2). Within the continents, the sequence is alphanumerical according to the GIVD ID. 
The field scope (4) contains a brief description of the content, while period (6) holds the years of the oldest and the youngest vegetation plot. According to the conditions for inclusion in GIVD (Dengler et al. 2011), databases of different statuses are accepted. The status (5) can be emerging (the database is planned or exists only in a preliminary version with a few vegetation plots and/or limited functionality), ongoing capture (the database is fully functional and data are added continuously), completed and continuing (the majority of past data within the scope have already been captured; now mainly new vegetation plots are being added), or finished (there are no longer activities to add further data). The next line contains the names and e-mail addresses of the database manager(s) (7), meaning the persons who currently curate the database and to whom data requests should be addressed. GIVD requires one database manager and up to two deputy database managers. All other persons who are making significant contributions to the database in terms of data, concept or maintenance or did so in the past (including the originator(s) of the database), but who are not currently serving as custodians are considered as "other authors". They are not included in the Fact Sheet itself but listed as authors of the Short Database Reports and in the online version of GIVD. When data from a database are used, credit to the full team of authors should be given, not only to the database manager(s). The database manager(s) can be identical with the owner (8) of the database, but the data can also be owned by another person or an organisation. This field is followed by the web address (9) of the associated website if available.

Regarding data requests, the reader can see information on data availability (10). The data can be available free online, free upon request, according to a specific agreement, after a blocking period, but also only with reduced precision, or they are not yet available. One can see if there is a possibility for an online upload (11) or online search (12) at the database's website. After providing some information about the database format (13), represented by the name of the database management system (e.g. MySQL, PostgreSQL, Oracle, Microsoft Access), the program (e.g. TURBOVEG; Hennekens \& Schaminée 2001) or the file type, we list possible export formats (14) because this is one technical aspect people need to know for possible merging of data from different sources.

The field publication (15) may provide a citation of another paper with a more detailed description of the database content. References to further descriptive publications as well as papers using the database for vegetation classification or other research are given in the web version of GIVD.

Some general methodological information regarding applied plot type(s) (16) (whether normal plots, nested plots and/or time series have been used) and the plotsize range (17) (smallest and largest plot area) follow. The number of plots in the vegetation database is provided as total plot observations (21), where each subplot in nested plot series and each recording date in time series is counted separately, and the number of nonoverlapping plots (18), where time series or nested-plot series are counted only once. Based on an estimate of nonoverlapping existing plots (19) - meaning all data that fall into the scope of the vegetation database including all data not yet digitized - the completeness (20) of the database is calculated. Furthermore, the number of sources (22) from which the vegetation-plot data originate (relevant for those databases that contain digitised data from literature sources), and the number of valid taxa (23), i.e. the taxa occurring in the plots without synonyms, is provided.

The fields 24-30 give an overview of the properties of the plot data contained in a database. The values are given as percentages, which usually sum up to $100 \%$, but in the fields 27-29 can exceed unity as some plots belong to more than one category. The fractions refer to the number of non-overlapping plots, except for sampling periods (30), which refer to total plot observation to cover also the time series.

As a first parameter, the proportional distribution by countries (24) is provided. Countries are given by their alpha-2 ISO code (Table 3) and arranged alphabetically.

Next are the percentages of vegetation plots representing certain formations (25). While GIVD online distinguishes 10 main formations (see Jansen et al. 2012), some of them had to be aggregated for the Fact Sheets because of space constraints. Here, we distinguish Forest (including semi-aquatic and terrestrial) and six Nonforest formations: aquatic, semi-aquatic (both including haline and fresh water), arctic-alpine, other natural, semi-natural, and anthropogenic.

Next, the percentage of plots that recorded the guilds (26) only trees and shrubs, all vascular plants, bryophytes, lichens, algae (the latter three categories referring to terricolous species), and nonterricolous taxa are given. This grouping deviates from the present online version of GIVD (http://www.givd.info) where woody vascular plants are distinguished from herbaceous vascular plants. While the intention of this categorisation was to list those guilds that would have been recorded if present, this was misunderstood by some users who gave values for woody vascular plants only when trees or shrubs were actually present, rendering the online values not comparable. Consequently, the new category only trees and shrubs contains the percentage of plots from the former category woody vascular plants minus that of herbaceous vascular plants if positive or $0 \%$ if negative. This correction is expected to give more realistic values than the original figures, but without distorting the correct interpretations of the field's definition. Based on the above-mentioned assumption, the numbers provided in herbaceous vascular plants have been kept unchanged, but the category was renamed to all vascular plants. We intend to implement this change in a future update of the online version, too.

The field environmental data (27) indicates the percentages of plots with information on attributes such as altitude, slope, or soil properties. The performance measure (28) contains the percentage of plots for which certain measures of abundance have been used, and geographic localisation (29) reports the number of plots that are recorded with different degrees of geographic accuracy. Finally, the percentage of plots sampled in certain sampling periods (30) (see Table 1 for categories) is also provided.

As some metadata of vegetation-plot databases might rapidly become outdated, particularly if a database is managed actively, the last line of the Fact Sheet provides the date of its compilation as well as the URI (31) to the respective metadata entry on the GIVD website. There, the most recent version of the metadata can be found, and we plan to provide an option to download up-to-date versions of the Fact Sheets. 


\section{Database Name (3)}

\section{Scope: (4)}

Status: (5)

Period: (6)

Database manager(s): (7)

Owner: (8)

Web address: (9)

Availability: (10)

Database format(s): (13)

Publication: (15)

Plot type(s): (16)

Non-overlapping plots: (18)

Total plot observations: (21)

Countries: (24)

Forest: - Non-forest: (25)

Guilds: (26)

Environmental data: (27)

Performance measure(s): (28)

Geographic localisation: (29)

Sampling periods: (30) Information as of 2012-07-12 further details and future updates available from http://www.givd.info/ID/<db_id> (31)

Fig. 1: Empty template of a GIVD Fact Sheet as it is used in the Long and Short Database Reports of this volume to summarise the key information of a GIVD-registered vegetation-plot database.

Table 1: Overview of the fields in the GIVD Fact Sheets and the possible values. If the database manager(s) did not provide data in a specific field, this is shown in the Fact Sheet as "[NA]" = not available.

\begin{tabular}{|c|c|c|c|}
\hline No. & Name & Description & Values / options \\
\hline$(1)$ & GIVD Database ID & GIVD's unique persistent identifier & (assigned by GIVD Steering Commitee) \\
\hline$(2)$ & Last Update & Last update of the metadata & (date) \\
\hline (3) & Database name & Proper name of the database & (plain text) \\
\hline$(4)$ & Scope & Brief outline of the scope of the data collection & (plain text) \\
\hline$(5)$ & Status & Progress and status in building the database & $\begin{array}{l}\text { Options: } \\
\text { emerging; ongoing capture; completed and } \\
\text { continuing; finished }\end{array}$ \\
\hline$(6)$ & Period & Oldest and youngest year of observations & (number) \\
\hline$(7)$ & Database manager(s) & $\begin{array}{l}\text { Name(s) and email address(es) of the current } \\
\text { contact person(s) }\end{array}$ & (plain text) \\
\hline$(8)$ & Owner & $\begin{array}{l}\text { The person / organisation who possesses the } \\
\text { database }\end{array}$ & (plain text) \\
\hline$(9)$ & Web address & The link to the database website, if available & URL http:// \\
\hline$(10)$ & Availability & How are the data accessible? & $\begin{array}{l}\text { Options: } \\
\text { free online; free upon request; according to } \\
\text { specific agreement; after a blocking period; } \\
\text { with reduced precision; not yet available }\end{array}$ \\
\hline$(11)$ & Online upload & Can the data be uploaded online? & Yes; No \\
\hline (12) & Online search & Can the data be searched for online? & Yes; No \\
\hline$(13)$ & Database format & $\begin{array}{l}\text { Management System, program or file type of the } \\
\text { stored data }\end{array}$ & $\begin{array}{l}\text { Options: } \\
\text { TURBOVEG; MS Access: MySQL; } \\
\text { PostgreSQL; Oracle; Excel; } \\
\text { other: (plain text) }\end{array}$ \\
\hline (14) & Export format & Format for data exchange & $\begin{array}{l}\text { Options: } \\
\text { TURBOVEG; MS Access; SQL; Excel; } \\
\text { Open Document; PDF; CSV file; plain text } \\
\text { file } \\
\text { other: (plain text) }\end{array}$ \\
\hline
\end{tabular}


Table 1 (continued).

\begin{tabular}{|c|c|c|c|}
\hline No. & Name & Description & Values / options \\
\hline$(15)$ & Publication & Publication describing the database & (plain text) \\
\hline$(16)$ & Plot type(s) & Type of plot record & $\begin{array}{l}\text { Options: } \\
\text { normal plot; nested plot; time series }\end{array}$ \\
\hline$(17)$ & Plot size range & Minimum and maximum size of the plot area & (numbers in $\mathrm{m}^{2}$ ) \\
\hline$(18)$ & Non-overlapping plots & $\begin{array}{l}\text { Number of plots that do not overlap (records in one } \\
\text { time series or in one nested-plot series together } \\
\text { count as one) }\end{array}$ & (number) \\
\hline$(19)$ & Estimate of existing plots & $\begin{array}{l}\text { Estimate of all plot data existing for the scope of } \\
\text { the database (including non-digital data) }\end{array}$ & (number) \\
\hline$(20)$ & Completeness & $\begin{array}{l}\text { Ratio of non-overlapping plots to the estimate of } \\
\text { existing plots }\end{array}$ & (number) \\
\hline$(21)$ & Total plot observations & Total number of vegetation-plots in the database & (number) \\
\hline (22) & Number of sources & $\begin{array}{l}\text { Number of different sources from which the plots } \\
\text { have been included }\end{array}$ & (number) \\
\hline (23) & Valid taxa & Number of occurring valid taxa in the database & (number) \\
\hline (24) & Countries & $\begin{array}{l}\text { Fraction of plots that originated from a certain } \\
\text { country }\end{array}$ & $\begin{array}{l}\text { (number) } \\
\text { (countries as alpha-2 ISO codes) }\end{array}$ \\
\hline (25) & $\begin{array}{l}\text { Forest / Non-forest } \\
\text { (Formations) }\end{array}$ & $\begin{array}{l}\text { Fraction of plots that cover the respective vegeta- } \\
\text { tion formations }\end{array}$ & $\begin{array}{l}\text { (number) } \\
\text { Categories: } \\
\text { Forest; } \\
\text { Non-forest: } \\
\text { aquatic; semi-aquatic; arctic-alpine; } \\
\text { natural; semi-natural; anthropogenic }\end{array}$ \\
\hline (26) & Guilds & Fraction of plots that recorded these guilds & $\begin{array}{l}\text { (number) } \\
\text { Categories: } \\
\text { all vascular plants; } \\
\text { only trees and shrubs; } \\
\text { bryophytes (terricolous or aquatic); } \\
\text { lichens (terricolous or aquatic); } \\
\text { algae (terricolous or aquatic); } \\
\text { non-terricolous taxa (epiphytic, saxi- } \\
\text { colous, lignicolous) }\end{array}$ \\
\hline (27) & Environmental data & Fraction of plots with information on environment & $\begin{array}{l}\text { (number) } \\
\text { Categories: } \\
\text { altitude; } \\
\text { slope aspect; } \\
\text { slope inclination; } \\
\text { microrelief; } \\
\text { soil depth; } \\
\text { surface cover other than plants (open } \\
\text { soil, litter, bare rock etc.); } \\
\text { soil pH; } \\
\text { other soil attributes; } \\
\text { land use categories }\end{array}$ \\
\hline (28) & Performance measure(s) & Fraction of plots applying the following measures & $\begin{array}{l}\text { (number) } \\
\text { Categories: } \\
\text { presence/absence only; } \\
\text { cover; } \\
\text { number of individuals; } \\
\text { measurements like diameter or height of } \\
\text { trees; } \\
\text { biomass; } \\
\text { other }\end{array}$ \\
\hline (29) & Geographic localisation & $\begin{array}{l}\text { Fraction of plots that were sampled with a certain } \\
\text { spatial accuracy }\end{array}$ & $\begin{array}{l}\text { (number) } \\
\text { Categories: } \\
\text { GPS coordinates (precision } 25 \text { m or } \\
\text { less); } \\
\text { point coordinates less precise than GPS, } \\
\text { up to } 1 \mathrm{~km} \text {; } \\
\text { small grid (not coarser than } 10 \mathrm{~km} \text { ); } \\
\text { political units or only on a coarser scale } \\
(>10 \mathrm{~km})\end{array}$ \\
\hline
\end{tabular}


Table 1 (continued).

\begin{tabular}{|c|c|c|c|}
\hline No. & Name & Description & Values / options \\
\hline (30) & Sampling periods & $\begin{array}{l}\text { Fraction of plots that was sampled in certain peri- } \\
\text { ods }\end{array}$ & $\begin{array}{l}\text { (number) } \\
\text { Categories: } \\
\quad \text { <1919; 1920-1929; 1930-1939; 1940- } \\
\text { 1949; 1950-1959; 1960-1969; 1970- } \\
\text { 1979; 1980-1989; 1990-1999; 2000- } \\
\text { 2009; 2010-2019; unknown }\end{array}$ \\
\hline (31) & State \& database URI & $\begin{array}{l}\text { Date of data export and link to the respective web } \\
\text { resource (URI) }\end{array}$ & (plain text) \\
\hline
\end{tabular}

Table 2: Background colours used for the Fact Sheets to indicate the continent(s) covered. The sequence below is also the sequence in which the Long and Short Database Reports are ordered . Multi = multiple continents (coded as 00); AF = Africa; AS = Asia; AU = Australia; EU = Europe; NA = North America; SA = South America.

\begin{tabular}{|c|c|c|c|c|c|c|}
\hline Multi & AF & AS & AU & EU & NA & SA \\
\hline
\end{tabular}

Table 3: Alpha-2 ISO codes and the official English short country names that are used in GIVD. Only countries are displayed for which at least one vegetation plot had been registered on 16 June 2012.

\begin{tabular}{|c|c|c|c|c|c|c|c|}
\hline$A D$ & Andorra & & Germany & KG & Kyrgyzstan & PA & Panama \\
\hline $\mathrm{AO}$ & Angola & DJ & Djibouti & $\mathrm{KP}$ & North Korea & PE & Peru \\
\hline$A R$ & Argentina & DK & Denmark & KR & South Korea & $\mathrm{PL}$ & Poland \\
\hline AT & Austria & EC & Ecuador & $\mathrm{KW}$ & Kuwait & PT & Portugal \\
\hline $\mathrm{AU}$ & Australia & EE & Estonia & $\mathrm{KZ}$ & Kazakhstan & RO & Romania \\
\hline$A Z$ & Azerbaijan & $E G$ & Egypt & LA & Laos & RS & Serbia \\
\hline $\mathrm{BA}$ & Bosnia and Herzegovina & ES & Spain & $\mathrm{LI}$ & Liechtenstein & RU & Russia \\
\hline $\mathrm{BE}$ & Belgium & ET & Ethiopia & LR & Liberia & SD & Sudan \\
\hline $\mathrm{BF}$ & Burkina Faso & $\mathrm{FI}$ & Finland & LS & Lesotho & SE & Sweden \\
\hline $\mathrm{BG}$ & Bulgaria & FR & France & LT & Lithuania & SI & Slovenia \\
\hline BJ & Benin & GA & Gabon & LV & Latvia & SK & Slovakia \\
\hline $\mathrm{BN}$ & Brunei & GB & United Kingdom & LY & Libya & SL & Sierra Leone \\
\hline $\mathrm{BO}$ & Bolivia & GF & French Guiana & MA & Morocco & SN & Senegal \\
\hline $\mathrm{BR}$ & Brazil & $\mathrm{GH}$ & Ghana & ME & Montenegro & SO & Somalia \\
\hline BW & Botswana & GN & Guinea & MG & Madagascar & SR & Suriname \\
\hline BY & Belarus & $G Q$ & Equatorial Guinea & MK & Macedonia & SV & El Salvador \\
\hline $\mathrm{BZ}$ & Belize & GR & Greece & ML & Mali & TD & Chad \\
\hline $\mathrm{CA}$ & Canada & GW & Guinea-Bissau & MN & Mongolia & TG & Togo \\
\hline CD & Congo & GY & Guyana & MR & Mauritania & TR & Turkey \\
\hline CF & Central African Republic & $\mathrm{HN}$ & Honduras & $M X$ & Mexico & TW & Taiwan \\
\hline CG & Congo-Brazzaville & HR & Croatia & MY & Malaysia & $\mathrm{TZ}$ & Tanzania \\
\hline $\mathrm{CH}$ & Switzerland & $\mathrm{HU}$ & Hungary & $M Z$ & Mozambique & UA & Ukraine \\
\hline $\mathrm{Cl}$ & Côte d'Ivoire & ID & Indonesia & NA & Namibia & UG & Uganda \\
\hline $\mathrm{CL}$ & Chile & IE & Ireland & NE & Niger & US & United States \\
\hline CM & Cameroon & IL & Israel & $N G$ & Nigeria & VE & Venezuela \\
\hline $\mathrm{CN}$ & China & IN & India & $\mathrm{NI}$ & Nicaragua & YE & Yemen \\
\hline $\mathrm{CO}$ & Colombia & IR & Iran & $\mathrm{NL}$ & Netherlands & ZA & South Africa \\
\hline CR & Costa Rica & IT & Italy & $\mathrm{NO}$ & Norway & ZW & Zimbabwe \\
\hline $\mathrm{CV}$ & Cape Verde & $\mathrm{JP}$ & Japan & NP & Nepal & & \\
\hline $\mathrm{CZ}$ & Czech Republic & $\mathrm{KE}$ & Kenya & $N Z$ & New Zealand & & \\
\hline
\end{tabular}

\section{References}

Dengler, J., Jansen, F., Glöckler, F., Peet, R.K., De Cáceres, M., Chytrý, M., Ewald, J., Oldeland, J., Finckh, M., Lopez-Gonzalez, G., Mucina, L., Rodwell, J.S., Schaminée, J.H.J., Spencer, N. (2011): The Global Index of Vegetation-Plot Databases (GIVD): a new resource for vegeta- tion science. - Journal of Vegetation Science 22: 582-597. CrossRef

Glöckler, F. (2012): Overview of the GIVD-registered databases. - In: Dengler, J., Oldeland, J., Jansen, F., Chytrý, M., Ewald, J., Finckh, M., Glöckler, F., Lopez-Gonzalez, G., Peet, R.K., Schaminée, J.H.J. [Eds.]: Vegetation databases for the 21st century. - Biodiversity \& Ecology 4: 89-94. Hamburg: Biocentre
Klein Flottbek and Botanical Garden. CrossRef

Hennekens, S.M. Schaminée, J.H.J. (2001): TURBOVEG, a comprehensive data base management system for vegetation data. - Journal of Vegetation Science 12: 589-591. CrossRef

Jansen, F., Glöckler, F., Chytrý, M., De Cáceres, M., Ewald, J., Finckh, M., Lopez-Gonzalez, G., Oldeland, J., 
Peet, R.K., Dengler, J. (2012): News from the Global Index of VegetationPlot Databases (GIVD): the metadata platform, available data, and their properties. - In: Dengler, J., Oldeland, J., Jansen, F., Chytrý, M., Ewald, J., Finckh, M., Glöckler, F., Lopez-Gonzalez, G., Peet, R.K., Schaminée, J.H.J. [Eds.]: Vegetation databases for the 21st century. - Biodiversity \& Ecology 4: 77-82. Hamburg: Biocentre Klein Flottbek and Botanical Garden. CrossRef
Falko Glöckler*

(falko.gloeckler@gmx.de)

Biodiversity Informatics, Global

Biodiversity Information Facility

(GBIF), Natural History Museum

Berlin

Invalidenstr. 43

10115 Berlin, GERMANY

Jürgen Dengler

(juergen.dengler@uni-hamburg.de) \& Jens Oldeland (jens.oldeland@uni-

hamburg.de)

Biodiversity, Evolution and Ecology

of Plants (BEE), Biocentre Klein

Flottbek and Botanical Garden,

University of Hamburg

Ohnhorststr. 18

22609 Hamburg, GERMANY
Florian Jansen (jansen@unigreifswald.de)

Landscape Ecology and Ecosystem

Dynamics (LEED), Institute of

Botany and Landscape Ecology,

University of Greifswald

Grimmer Str. 88

17487 Greifswald, GERMANY

Robert K. Peet (peet@unc.edu) Department of Biology, CB\#3280, University of North Carolina Chapel Hill, NC, 27599-3280, UNITED STATES

*Corresponding author 